\title{
Acolhimento no cotidiano dos auxiliares de enfermagem nas Unidades de Saúde da Família, Londrina (PR)
}

\author{
Nurse's daily reception in Family Health Units \\ in Londrina, Paraná State
}

\author{
Sônia Regina N ery ${ }^{1}$ \\ Elisabete de Fátima Polo deAlmeida Nunes ${ }^{2}$ \\ Brígida Gimenez de Carvalho ${ }^{2}$ \\ Regina M elchior ${ }^{2}$ \\ Rossana Staevie Baduy ${ }^{2}$ \\ JosianeVivian Camargo de Lima²
}

\footnotetext{
${ }^{1}$ Autarquia M unicipal de

SaúdedeLondrina. Rua Attilio Octávio Bisatto 480, Centro. 86010-340 Londrina PR. sorenery@yahoo.com.br ${ }^{2}$ Departamento deSaúde Coletiva, Centro de Ciências da Saúde, Universidade Estadual de Londrina.
}

Abstract This paper analyses the auxiliary nurses' perception on the work of the Family $\mathrm{H}$ ealth team regarding users' receptiveness as a technology in the relationship with patients and community in Londrina, Paraná State, Brazil. It is a qualitative re search, which data was collected during a focal group. Thematic analysis of the content was performed for data analysis. Results show that auxiliary nurses have sensibility, are committed, and feel responsible for users' receptiveness, and recognize the importance of an integral and effective attention. They report knowing better the reality of thefamilies' lives since the implementation of the Family $\mathrm{H}$ ealth Program, but highlight the fact that not all of them perform activities outside the unit. Contradictions have also been noted regarding the patients' rights provided by the U nified $\mathrm{H}$ ealth System, mainly about the universality of access. One of the reported difficulties was the increase of demand after the implementation of the Family $\mathrm{H}$ ealth Program. This situation presents itself as a challenge to change the attention model, and it is necessary to reorganize the process of work as well as to incorporate other fields of knowledge in order to promote the practice of receptiveness, and the integration of intra and extra activities at the unit.

Key words Servicesassessment, Family health team, Nurse's role, U ser embracement
Resumo Analisa-sea visão dosauxiliares de enfermagem sobrea prática das equipes desaúde da família em Londrina (PR), quanto à adoção do acolhimento como tecnologia na relação com o usuário e comunidade. Trata-se de uma pesquisa qualitativa; os dados foram coletados por meio de grupo focal e analisados utilizando-se a análise de conteúdo através da análise temática. Os resultados mostraram queos mesmos têm sensibilidade, compromisso eresponsabilidade para acolher o usuário, e reconhecem a importância do atendimento integral e resolutivo. Relatam conhecer melhor a realidade vivida pelas famílias, a partir da implantação da saúde da família, mas destacam o fato dequenem todos os auxiliares de enfermagem realizam as atividades externasà unidade. Também foram percebidas contradições quanto aos direitos dos usuários de SUS, principalmente no que se refere à universalidade do acesso. U ma das dificuldades citadas foi o aumento da de manda ocorrido após a implantação do Programa Saúde da Família. Tal situação apresenta-se como um dos desafios para mudança do modelo de atenção, sendo necessária a reorganização do processo de trabalho e a incorporação de outros campos de conhecimento, no sentido de que 0 acolhimento ocorra, integrando as atividades intra e extra unidade. Palavras chave Avaliação dos serviços, Programa Saúdeda Família, Papel do auxiliar deenfermagem, acolhimento 


\section{Introdução}

O acolhimento nas unidades saúde da família (USF) apresenta-secomo uma potencial ferramenta na consolidação do Sistema Ú nico de Saúde (SUS) e estudá-lo remete a reflexões a respeito das relações no cotidiano dos serviços de saúde, no compromisso com a demanda em determinado território e com a realidade sanitária na qual vivem as pessoas.

0 modelo atual de saúde, ainda hegemônico, caracteriza-seem focalizar a atenção na doença, centrado na assistência médica individual, fragmentada, especializada e direcionada à demanda espontânea. Da forma como está estruturado, mesmo com a expansão dos serviços em quantidade adequada aos parâmetros assistenciais, sua lógica de organização mantém o modelo dentro de um paradigma restrito, direcionado aos danos e, portanto, predominantemente no campo curativo. Como consequência, não se ampliam as intervenções que visam evitar os riscos de adoecer e morrer ${ }^{1}$.

$\mathrm{Na}$ perspectiva de superar esse dilema, muitos municípios utilizaram a estratégia da saúde da família (ESF), para a reorganização da prática assistencial em novas bases e critérios, caracterizando-se como a principal resposta, ofertada no âmbito da assistência pelosórgãos governamentais, para supe ração da crise do modelo atual de atenção à saúde².

Esta estratégia prioriza ações de prevenção, promoção e recuperação da saúde das pessoas, de forma integral e contínua, procurando facilitar o acesso aos serviços de saúde e um atendimento personalizado, mais acolhedor, mantendo uma relação de vínculos direta com a clientela eresponsabilidades com relação à manutenção da saúde daquela comunidade ${ }^{1}$.

Para operacionalizar essa estratégia, diferentes tecnologias devem ser empregadas. As tecnologias envolvidas no trabalho em saúde podem ser classificadas em trêstipos: duras, leve-duras eleves. As tecnologias duras seriam os equipamentos do tipo máquinas, normas e estruturas organizacionais; as leve-duras incluem os saberes bem estruturados que operam no processo de trabalho em saúde, como a clínica médica, a epidemiologia e a clínica psicanalítica e as leves são aquelas envolvidas nas relações de produção de vínculo, acolhimento, autonomização e gestão como forma de governar processos de trabalho ${ }^{3}$.

Neste sentido, 0 acolhimento é uma tecnologia leve que deve ser utilizada na perspectiva de implantação de novas práticas de saúde.

A palavra acolhimento significa: 0 ato ou efeito de acolher, recepção. Atenção, consideração. Refú- gio, abrigo, agasalho. A colher significa dar acolhida ou agasalho a. Dar acolhida a; receber. Atender; re ceber. Dar crédito a, dar ouvidosa. Admitir; aceitar. Tomar em consideração; atender. Abrigar, agasalhar. Agasalhar-se, hospedar-se. Abrigar-se, recolher-se. Refugiar-se; amparar-se4.

0 acolhimento é apresentado como a possibilidade de universalizar o acesso, abrir as portas dos serviços de saúde a todos os usuários que dela necessitarem, possibilitando a reorganização do sistema de saúde ${ }^{5}$ Também destaca-se a importância de 0 acolhimento ocorrer em todos os locais e momentos em uma unidade de saúde 6 acolhimento é, portanto, um recurso tecnológico importante e o trabalhador necessita utilizar todo o seu "saber" para atender as necessidades do usuário e assim garantir a qualidade nos serviços de saúde.

Para M atumoto ${ }^{7}$, em seu estudo na rede básica de serviços de saúde e seus componentes, 0 acolhimento desperta uma necessi dade de ol har para como estão organizados os serviços de saúde e seu modelo de assistência. Ao mesmo tempo, nos estimula a repensar atitudes para mudar este panorama [...].

A expansão da ESF no município de Londrina, Paraná, Brasil, deu-se no ano de 2001, como possibilidade de mudanças, na qual se procurou preservar os aspectos positivos da atual organização dos serviços de saúde, incorporando novas práticas sanitárias visando à implementação do SUS. Para a constituição das equipes de Saúde da Família, foram contratados agentes comunitários de saúde (ACS) e os trabalhadores de saúde da rede de atenção básica (médicos, enfermeiros e auxiliares de enfermagem) foram convidados a participar das equipes com ampliação de sua carga horária. No entanto, enquanto para as categorias de médico e enfermeiro houve contratação complementar para compor as equipes, para os auxiliares de enfermagem, ocorreu apenas a ampliação de carga horária dos que já que já atuavam nas unidades. As equipes foram vinculadas às unidades de saúdee pretendia-se que elas fossem, nesteprocesso, transformando-se em USF, isto é, incorporando os princípios da ESF à organização do trabalho das tradicionais unidades básicas de saúde. Atualmente, são 101 equipes, cobrindo 75\% da população do município ${ }^{8}$.

0 monitoramento do trabalho das equipes de Saúde da Família vem sendo realizado por meio da pactuação de metas, da análise de indicadores de morbimortalidade e da produção de serviços registradosnos sistemas de informação já existentes (ex.: Sistema de Informação sobre M ortalidade - SIM , Sistema de Informação sobre N ascidos Vivos - SI- 
NASC) e do SIAB (Sistema deInformação daAtenção Básica). Greene, citado por $\mathrm{H}_{\text {artz }}{ }^{9}$, salienta que nem semprea qualidade deuma intervenção ébem captada por um sistema baseado em metas, pois se deve preocupar também com os meios utilizados para obtêlas. Para isso, outros campos de conhecimentos implicados na produção de ações acolhedoras, de escuta qualificada e de vínculo entre trabalhadores e usuários devem ser considerados ${ }^{10}$.

0 auxiliar de enfermagem (AE) tem papel importantee decisivo no encontro com o usuário que procura atendimento nas unidades de saúde. Em termos quantitativos e considerando sua relevância no processo de atenção básica, os auxiliares constituem o contingentemais expressivo entre os trabalhadores da equipe de enfermagem e de toda área da saúde. No Brasil, a representatividade desta categoria situa-se em $50 \%$ dos trabalhadores de saúde. No município de Londrina, OS AE representam $43 \%$ dos trabal hadores da equipe ${ }^{11}$.

0 presente artigo tem por objetivo analisar a compreensão dos trabalhadores AE sobre a prática cotidiana das equipes de Saúde da Família, quanto à adoção do acolhimento como tecnologia na relação com o usuário e comunidade, e faz parte de um projeto maior intitulado "Reorganização das práticas sanitárias no Sistema M unicipal de Saúde: a Estratégia Saúde da Família - um retrato do processo".

\section{Metodologia}

A opção metodológica definida para a pesquisa foi abordagem qualitativa, utilizando-se a técnica do grupo focal. Estemétodo possibilita pensar o coletivo de uma temática que é parte integrante do cotidiano das pessoas reunidas, conhecer o processo dinâmico de interação entre os participantes, observar como as controvérsias se manifestam e são resolvidas, reproduzindo os processos de interação que ocorrem no cenário de estudo fora dos encontros grupais ${ }^{12}$.

Foi realizado um grupo focal com nove auxiliares de enfermagem que atuavam em três USF do município de Londrina, duas delas localizadas na área urbana do município e uma, na área rural. Essas unidades de saúdeforam escolhidas por apresentarem uma boa avaliação de qualidade, segundo a gerência do serviço municipal, permitindo estudar as práticas predominantes dos auxiliares no atendimento aos usuários do SUS. É importante ressal tar que estas unidades possuíam estrutura e número de trabalhadores semelhantes às demais unidades do município.
Coube às gerentes das unidades de saúde a definição dos trabalhadores participantes do grupo focal, considerando os seguintes critérios: estar atuando na unidade há no mínimo seis meses, dispor de representantes do sexo feminino e masculino e das diferentes equipes de Saúde da Família deuma mesma unidade enão apresentar dificuldade de se expressar.

0 grupo focal foi realizado em novembro de 2004 por duas pesquisadoras integrantes da equipe de pesquisa, sendo que uma atuou como moderadora e outra, como observadora. As questões norteadoras do grupo focal versavam sobre a organização do serviço, além de uma possuir questão específica sobre o acolhimento; no entanto, a unidade de análise utilizada para esse artigo foi a do material do grupo focal como um todo.

A atividade foi gravada eposteriormente transcrita. Para análise dos dados, utilizou-se da análise de conteúdo ${ }^{13}$.

A partir da análise do material obtido, foram realizados, manualmente, recortes para a apreensão dos conteúdos manifestados. Foram extraídos os seguintes temas:

a) A sensibilidade dos auxiliares de enfermagem para acolher;

b) A organização do processo de trabalho e acolhimento;

c) Os espaços formais de socialização do trabalho - espaços de planejamento e avaliação.

A pesquisa foi aprovada pelo Comitê deÉtica e Pesquisa da Universidade Estadual de Londrina, por meio do parecer CEP 027/04 e cadastrada no CNPq, desde novembro de 2004, com concessão de auxílio financeiro.

Os trabalhadores participantes foram identificados na análise de suas falas pela sigla $A E$, seguida de um número de um a nove, determinado de maneira aleatória, para garantia de seu anonimato.

\section{Resultados ediscussão}

Sensibilidade do auxiliar de enfermagem para acolher

0 acolhimento pressupõe que o encontro entre trabalhadores da equipe de saúde com os usuários seja marcado pela disponibilidade em receber, escutar e tratar humanizadamente, considerando suas necessidades e potencialidades, estabelecendo, desta maneira, uma relação de interesse, confiança e apoio mútuo ${ }^{14}$.

0 encontro é o momento do trabalho em que dois sujeitos, usuário e trabalhador de saúde, nes- 
te caso 0 auxiliar de enfermagem, produzem uma relação de troca, pois ambos são portadores de necessidades e desejos, e nesta relação produz-se em ato al go que existe para os "dois" eque não tem existência sem este encontro. Este é um momento do trabal ho em saúde em que se desvela a autonomia do trabalhador na busca ou não de processos acolhedores de produção do cuidado em saúde ${ }^{15}$.

Os AE apresentaram uma compreensão e sensibilidade de que 0 acolhimento já começa quando o paciente põeo péno posto de saúde (AE 2). Enfatizaram também que a postura do trabalhador, ao receber o usuário, pode demonstrar cordialidade, aten ção e respeito, exercendo suas funções de forma humanizada.

Os auxiliares manifestam a vontade de realizar um atendimento acolhedor no encontro com o usuário, chamando-o pelo nome, cumprimentando-o, orientando-o, conversando, buscando atender suas necessidades, mas referem que 0 acolhimento depende do estado emocional do trabalhador: Acolhimento, acho que quase todos os nossos funcionários fazem, tirando um ou outro queé mais nervoso ( $A E$ 4).

Consideram o acolhimento como possibilidade de, no encontro, buscar formas de enfrentamento dos problemas de saúde apresentados no dia-a-dia pelo usuário na USF, a maioria sempre procura acolher bem os pacientes, tentar, dentro do possível, resolver o problema dele (AE 4).

Nestes termos, verificou-se que os informantes buscam realizar o acolhimento em seu cotidiano e consideram-no importante para o desenvolvimento das relações entre trabalhadores e usuários.

A empatia foi apresentada como possibilidade para 0 atendimento acolhedor: Então como eu não gosto que faça para mim, então eu não vou fazer para ninguém (AE 9).

Conhecer a realidade do usuário, sua condição de levar a vida, contribui para elaboração do projeto do cuidado com o mesmo. Verifica-se a seguir a compreensão dos AE sobre a importância que é atribuída para o conhecimento dos aspectos socioeconômico ecultural dos usuários: Com certeza cada área tem um perfil, por exemplo, você não pode ver um paciente aqui do centro, como um paciente lá da $X$ [nome de uma USF], você não pode orientar uma carne para um paciente de lá porque ele não vai ter carne para comer, fruta. Tanto nós, como os médicos, temos que saber a orientação que vai fazer. Você vai ter que perguntar para a mãe, por exemplo, o que você tem em casa para a criança comer? (AE 4).

Em outro momento, o diálogo, a discussão sobre os problemas apresentados pelos usuários, a troca de informações entre a equipe, é referida como a possibilidade de desencadear compromisso e responsabilidade no atendimento ao usuário: Tem o entrosamento muito grande como, por exemplo, para chegar no ACS da área e dizer: olha, essa criança é da sua área, ela veio aqui e eu estou encaminhando para o hospital. É uma confiança muito grande que eu tenho de que essa criança, na mesma semana será visitada pelo ACS (AE8).

A responsabilização na saúde, para os trabaIhadores da área, pode ser entendida como a capacidade de assumir a responsabilidade pelos problemas de saúde de um usuário e comunidade ${ }^{16} \mathrm{e}$ tanto o compromisso como a responsabilização são aspectos fundamentais para se alcançar a integralidade da atenção.

Percebeu-se nas falas a procura pela integralidade: É uma atenção, é um exame, é a busca no fundo, nós buscamos hoje o paciente como um todo. Eu acho, quando se assume um paciente, um atendimento, você tem que ser responsável (AE 2).

A importância da escuta acolhedora durante 0 atendimento em saúde possibilita o interpretar, 0 pensar, o sentir e agir do outro, de acordo com a realidade onde a pessoa está inserida ${ }^{17}$. Na mesma direção, a compreensão da realidade vivida pelos usuários fortalece o vínculo da equipe de saúde e amplia a possibilidade de resolução de problemas apresentados na USF.

A integração do trabalho realizado dentro da USF e as atividades realizadas fora da unidade, ou seja, na família, na comunidade, representam formas de identificar situações de risco, como apresentado no relato: Se ela está com desvio para de pressão, se essa criança tem um desvio, se está sendo prejudicada pelos familiares, um assédio, uma coisa assim, estou achando essa criança estranha, porque às vezes não tem como abordar esseassunto, mas com a visita do auxiliar, ele pode averiguar e chegar a uma posição de violência sexual, ou alguma coisa (AE 9).

Verificou-sequeestão presentes nos depoimentos dos AE uma sensibilidade para a escuta, a importância da visão integral do usuário, do compromisso e da responsabilidade na resolução dos problemas de saúde apresentados pelo mesmo e que se constituem como vetores que desencadeiam todo um processo que pode culminar em práticas acolhedoras.

A pesar das falas apresentadas delinearem uma sensibilidade e uma concepção da importância de se prestar um bom atendimento aos usuários, um dostrabalhadores refere-se ao atendimento do SUS, como um serviço gratuito: E sem custo nenhum do bolso deles. Eles têm tudo ali enão pagam nada, éde graça (AE 2). 
As concepções dos profissionais, sua subjetividade, sua compreensão sobre direitos, cidadania, podem influenciar no atendimento prestado, como neste caso em que o trabal hador entende o sistema de saúde apenas como uma benesse aos menos favorecidos e não um direito constitucional.

$N$ este momento de encontro e diálogo entre dois sujeitos, observa-se que o $\mathrm{AE}$ se ressente pela não valorização pela comunidade do seu trabalho e do atendimento oferecido na USF e acredita que esta postura ocorre devido ao desconhecimento que o usuário tem do trabalho realizado: Só que eu acho que o principal problema é que não é valorizado nem um pouco, é muito raro um ou outro falar muito obrigado ou alguma coisa. Eu acho que está faltando esse tipo orientação para a população, como usar bem a unidade para todo mundo. Porque eu acho quenem é culpa deles, mas eles não sabem, eles não valorizam, não entendem o que éa prevenção, 0 papel do posto de saúde (AE 2).

0 trabalhador da saúde, por vezes, frustra-se pela falta de condições para 0 atendimento acolhe dor e acredita que o usuário não contribui nesta relação: Eu acho que eles têm que ser reeducados também. Porque é difícil e dependendo do local de trabalho é pior ainda, eles chegam batendo no balcão, discutindo, é difícil também (AE 4 ).

A prática em saúde é dependente também dos valores morais, éticos, ideológicos esubjetivos dos profissionais. Sendo assim, trabalhadores e usuários são mutuamente afetados nesse encontro. A possibilidade de escuta depende dos sentimentose afetos mobilizados, tanto pelo usuário no trabaIhador, como pelo trabalhador no usuário ${ }^{18} \mathrm{etam}$ bém pela forma como o processo de trabalho está organizado.

A organização do processo de trabalho

Cada USF empreende ações nos serviços que visam garantir o acolhimento ao usuário. Assim, a organização do processo de trabalho écomponente vital para a realização do acolhimento, devendo organizar-se para o trabal ho na comunidade e na própria unidade.

A organização do processo de trabalho na comunidade

Com a implementação da ESF no município, ocorreu a delimitação da área de responsabilização de cada equipe da unidade. Essa adscrição da clientela assistida pela equipe permitiu um maior conhecimento da comunidadee deseus problemas de saúde, fazendo com que os usuários que não eram atendidos pela USF de referência fossem visitadose acompanhados pela equipe responsável.

Antes da implantação da ESF, os trabalhadores já possuíam conhecimento e informações sobre 0 território, porém este saber tornou-se mais aprofundado, passou a ser sistematizado e apoiado pelas normas da instituição, como é apontado a seguir: Anteriormente, nós já fazíamos visitas, mas a intensidade era um pouco menor. Com a entrada do PSF, conseguimos observar e conhecer melhor a sua área, a ver o pacientequenão frequentava essa U nidadee saber o motivo. Resumindo, passamos a conhecer melhor a população onde trabal hamos (AE 6).

A equipe de saúde necessita sair a campo, realizar VD, contribuindo, desta maneira, ao planejamento eações para enfrentamento dos problemas, uma vez que "a responsabilidade da equipe não se limita nunca a quatro paredes" 15 .

Como citado anteriormente, no início do desenvolvimento da ESF em Londrina, houve ampliação da carga horária dos trabalhadores que se incorporaram formalmente às equipes de saúde da família, preenchendo as exigências do M inisté rio da Saúde. Essa não vinculação de todos os auxiliares de enfermagem às equipesfez com queaque les que não realizaram expansão da carga horária não se sintam integrantes da equipe Saúde da Família e não realizem atividades externas a USF: Só que quem não é do PSF não sai nas visitas (AE 2). Porém, a reconhecem como uma estratégia importante da atual organização dos serviços da atenção básica, conforme o relato: Porque existe o acamado que precisa ir agora e éárea dele, ele é obrigado a ir lá, já por uma organização que todo mundo acaba cedendo porque acha que é o justo é o certo, ele tem que ir mesmo (AE 8).

Os trabalhadores que ampliaram carga horária avaliam que, por permanecerem por mais tempo na unidade e por saírem para atividades externas à USF, possuem maior facilidade em acompanhar a evolução dos usuários e formar vínculo: Eu acho assim, que, como equipe, nós trabalhamos realmente, eu fico oito horas no posto, então você acaba convivendo, vendo como o paciente está, se o paciente foi internado ou não foi só que o restante (quem não ampliou a carga horária), não dá tempo para isso, não tem tempo pra se integrar muito ( $A E 3$ ).

Uma estratégia implementada em uma unidade para ampliar a integração da equipe eo envolvimento no atendimento domiciliar foi a incorporação das atividades extra muros na escala de todos os AE, conforme relato: Vamos citar um exemplo: D ona M aria sofreu AVC, então ela sabe que está com AVC, o nosso médico sabe, el e programa a visita dele para quinze dias. Nós temos nossas responsabilida- 
des, se é curativo da Dona Maria, se é para ver a pressão, se tem al gum exame para colher, então isso é responsabilidade nossa, então tem funcionário na escala uma vez por semana, para as visitas (AE 1).

Apesar da estratégia utilizada nesta USF, nas outras esta situação mantém-se como um problema a ser enfrentado, isto é, uma divisão em quem é do PSF e quem não é, etambém no tempo, atividades do PSF são aquelas realizadas nas duas horas que os trabalhadores ampliaram. Assim, um dos desafios que emerge ao mexer na organização do processo de trabalho é o de reconhecer os diversos interesses e subjetividades presentes no trabalho em saúde em suas diversas formas de manifestação na prática cotidiana.

Em estudo realizado, as dificuldades da implantação do acolhimento também apontaram que a conciliação do trabalho de assistência dentro da unidade com o trabalho "extra-muros" é um desafio².

Uma outra dificuldade sentida no trabal ho desenvolvido junto à comunidade refere-se à necessidade da inclusão de outros saberes no trabalho da equipe Saúde da Família: Eu só queria colocar assim, que viessem mais profissionais, tipo nutricionista, professor de educação física, psicólogo, fisioterapeuta. U m apoio (AE 9).

A USF é produtora de serviços de saúde e não é constituída por apenas um trabalhador, mas por uma equipe que produz intervenções necessárias na oferta de cuidados à saúde junto aos usuários, família e comunidade. Desta forma, o trabal ho coletivo deve se sustentar em um conhecimento que inclui as determinações biopsicossociais de saúdedoença. Logo, a assistência à saúde passa a ter característica de trabal ho coletivo e complexo e a interdisciplinaridade e a multiprofissionalidade são elementos necessários no seu desenvolvimento ${ }^{19}$.

A organização do processo detrabal ho na USF

OSAE mencionam que 0 aumento da demanda de usuários, sem a consequente ampliação de trabal hadores de saúde e de espaço físico, ocasiona desgaste que repercute na qualidade dos serviços prestados e também diretamente na sobrecarga de trabalho e na demora pelo atendimento.

0 aumento da demanda na USF é explicado pelos $\mathrm{AE}$ em função de que: aumentou esse pessoal do convênio, aumentou mais a busca que fazemos $e$ os funcionários continuam os mesmos. $N$ ão mudou ninguém, não aumentou ninguém ( $A E 3)$.

Exemplo disso é a pós-consulta, momento em que são entregues os medicamentos aos usuários e são feitas orientações gerais em relação à consulta realizada, e que pelo grande número de atendi- mentos, sem garantia de privacidade, há interferência no acolhimento ao usuário e provoca desgastes ao trabalhador: Porque tem mãe quevai com cinco crianças, se está orientando um, ela entra junto, às vezes tem três na sala, daí fica aquelezunzunzum, aí entra um pacientemais um emaisum. Deus me livre, você endoida ( $A E$ 4).

O número excessivo de atendimentos pode levar o funcionário a executar seu trabalho mecanicamente. Além disso, como apresenta Matumoto ${ }^{7}$ em seu estudo, a não existência de um espaço privativo interfere no acolhimento, na relação usuário-trabalhador, fazendo com que não seja respeitado o espaço do outro.

Uma outra variável queinterfereno acolhimento e aparece nas falas dos AE está relacionado ao tempo dispensado no atendimento: Porque o nosso atendimento não émal feito, a consulta do médico não é de quinze minutos, é de muito mais. É uma atenção, éum exame, éa busca no fundo, nós buscamos hoje o paciente como um todo ( $A E 2$ ).

Denota-se, na fala a seguir, que os trabalhadores ouvidos reconhecem como dificuldade em seu trabal ho cotidiano o fato dos usuários reclamarem da demora do atendimento e sentirem-se pressionados. Esta situação pode interferir neste encontro e na descoberta das reais necessidades do usuário: A pressão do paciente, acho queéo problema. H ojeeu estava no posto quando chegou uma pessoa eperguntou se tinha vacina, pedi para que aguardasse um pouquinho, pois estava atendendo e já falaria com ela, mas logo escutei: 'Vai demorar'? e disse que não aguentava mais ouvir vai demorar (AE 2).

Diante da situação instalada, a pressão vivenciada no dia-a-dia da USF leva o trabalhador a apresentar distúrbios e sua saúde também fica comprometida: Nós estamos aqui há dez ou onze anos na prefeitura, tem muitos, eu mesmo já tive distúrbio psiquiátrico, tem muitos funcionários que já tiveram esse distúrbio ( $A E 4)$.

0 cotidiano do trabalho também dificulta as inter-relações entre os trabal hadores: Tem dia que não conseguimos conversar um com o outro, falar alguma coisa, é só um bom dia (AE 9).

Estes depoimentos reforçam uma tendência verificada em muitas situações do atendimento à saúde em que predomina o caráter imediatista da sociedade, em que o tempo é priorizado como requisito de qualidade, como apresentado a seguir: Essa lógica da velocidade nos transforma em pessoas muito ocupadas, sem tempo para nada. Essa lógica impõe uma pressa nos trabalhadores e nos usuários, atendimentos rápidos, medicamentos com efeitos instantâneos, desaparecimento imediato dos sintomas, tudo correndo, tudo rapidinho! ${ }^{18}$. 
Os AE demonstram preocupação no acolhimento e buscam diminuir o tempo de espera para 0 atendimento em consulta médica. Entretanto, relatam as dificuldades internas e externas para 0 agendamento de consultas por horário e a incorporação destas alternativas em função do atraso do médico e do usuário quanto ao horário agendado, gerando conflitos entre a equipe ea população, e há ainda o entendimento de alguns funcionários de que o usuário do SUS pode esperar pelo seu atendimento. Isso tudo faz com que a equipe recue nas propostas de mudança.

O utra coisa nessa história do acol himento é trabalhar isso, éachar queo pacienteédo SU S então ele pode esperar, eu já ouvi isso da boca de um profissional e eu fico chocado (AE 6).

Verifica-se quenem todos os trabalhadores têm incorporado à sua prática a noção de saúde enquanto direito de cidadania. Essas contradições apontam a necessidade de discutir com os trabaIhadores os princípios e diretrizes do SUS em sua prática cotidiana.

Espaços formais de socialização do trabalho

- espaços de planejamento e avaliação

Foi manifestada, pelos $A E$, a existência de espaços formais para discussão nas USF, agendados com antecedência erealizados periodicamente. São momentos de avaliação das ações desenvolvidas, discussão de problemas e tomada de decisão, que se configuram de diferentes formas, considerando a organização interna da unidade: reunião das equipes Saúde da Família, reunião USF, reunião por grupos de trabalhadores responsáveis pelos programas. Porque é justamente na quinta-feira, fecha-se o posto uma hora, então tentamos resolver, nós conversamos a respeito dos problemas, dos programas (AE 1).

0 reconhecimento, tanto por parte do trabaIhador como do usuário e da sociedade, do sentido e do resultado de seu trabalho, da sua "obra" 20 , é identificado quando o trabalhador aponta a importância da sua participação no planejamento e avaliação das ações na USF, estar sabendo o que está acontecendo na minha [sua] área de abrangência (AE 6).

Ao mesmo tempo, referem dificuldades para viabilizar estas reuniões, considerando os diferentes turnos de trabalho dos $A E$ ea reunião não sendo utilizada para avaliação do trabalho e tomada de decisão, mas sim como um espaço apenas informativo: A coordenadora $Y$ faz a reunião do mês, coloca os encaminhamentos da USF, da vila, do programa de asmas, esó (AE 3).
A participação do trabalhador como sujeito no processo detomada de decisão énecessária e contribui para 0 acolhimento das necessidades apresentadas pelo usuário. Asreuniões possibilitam a equipe de Saúde da família caminhar além de um trabalho técnico hierarquizado, em um processo que privilegiea interação social entre os trabalhadores, com maior horizontalidade e flexibilidade dos diferentes poderes, fortalecendo a equipe multiprofissional ${ }^{19}$. Estes momentos de conversa possibilitam o enfrentamento dos conflitos que são constitutivos do trabalho em saúde.

Percebe-se nesses espaços de planejamento e avaliação do trabal ho quea gerência da unidade de saúde tem um papel fundamental. Para os auxiliares, a gerência deve assumir postura de liderança, estimulando a reflexão e envolvimento dos trabaIhadores com os objetivos institucionais de forma a atender às necessidades de saúde da população.

As características do trabalho de gerência desempenhado pelas enfermeiras coordenadoras da USF são vistas como determinantes para estimular na equipe de trabalhadores a utilização do conhecimento dos problemas de saúde, dos indicadores de saúde e situações de risco da comunidade para o desenvolvimento de suas atividades cotidianas Liderança é aquela capaz de levantar nas pessoas um senso crítico (AE4).

No entanto, ficou evidenciado que nem todos os enfermeiros coordenadores possuíam preparo específico para essa função. Isso reafirma a importância de se trabal har com a mudança na formação dos profissionais de saúde, no processo de educação permanente, como possibilidade de provocar, nos diferentes sujeitos da área da saúde, reflexões sobre o modo de agir, o trabal ho em equipe, a qualidade da atenção individual e coletiva ea organização do sistema de saúde como redeúnica.

\section{Conclusão}

A partir das considerações tecidas sobre as falas dos $A E$, identifica-se a sensibilidade, o compromisso, a responsabilidade e o reconhecimento da importância do acolhimento no atendimento integral e resolutivo aos usuários na USF. No entanto, persistem algumas contradições, como em relação aos direitos constitucionais dos usuários, 0 que evidencia as diferentes concepções de saúde e do SUS operando na prática destes trabalhadores de saúde.

No momento do encontro trabalhador eusuário, vários fatores foram apontados como obstáculos para o desenvolvimento do trabalho acolhe- 
dor, como a pressão da demanda, que gera um tempo reduzido para o atendimento, espaço físico inadequado e o imediatismo inerente a sociedade atual. Estes fatores geram sentimentos de angústia, insatisfação euma ten são constante no cotidiano destes trabalhadores.

$\mathrm{Na}$ análise da organização do processo de trabaIho, observa-se que, com a implantação da saúde da família, os trabalhadores passaram a conhecer me Ihor o território e os problemas de saúde da comunidade, mas há uma parcela de $\mathrm{AE}$ que não realiza atividades externas à USF, não se apropriando da realidadedo usuário, desua condição delevar a vida. Esta situação gera dificuldades na articulação entrea atenção à demanda espontânea eàs ações de prevenção dos agravos e promoção da saúde a serem realizadas junto às famílias e território, interferindo no acolhimento ena construção de vínculos.

Enfatizou-se a importância da atuação da gerência da USF, no sentido de estimular a consolidação do trabalho coletivo eviabilizar espaços for- mais de socialização, planejamento e avaliação do trabalho e com isso propiciar a discussão e adoção de estratégias que venham a qualificar 0 atendimento em saúde.

A partir dos resultados apresentado, é possível afirmar que há uma predisposição dos AE de praticarem 0 acolhimento no seu cotidiano, sendo necessárias reflexões e modificações do processo de trabal ho, incluindo um estudo sobre a adequação numérica dos auxiliares de enfermagem existentes nas unidades de saúde da família, para que o acolhimento se torne viável.

Este estudo podenão ter reproduzido de forma global a compreensão dos $A E$, pois uma pesquisa é sempreuma visão parcial do todo e, por outro lado, é permeada pela visão de mundo do pesquisador e por seu arcabouço teórico. Entretanto, mesmo parciais, consideramos que esses resultados podem contribuir com o planejamento e mudanças nas práticas dos trabalhadores com vistas a acolher as necessidades de saúde dos usuários.

\section{Colaboradores}

SR Nery foi responsável pela concepção teórica do projeto principal com definição de metodologia, sistematização dos temas de análise e redação do artigo, atendendo as sugestões dos demais autores e revisão. EFPA Nunes, pela condução do grupo focal, sistematização dostemas de análise, redação e revisão. R M elchior, pela redação e revisão. RS Baduy, pela concepção térica do projeto principal com definição de metodologia, sugestões detemas de análise, redação e revisão. BG Carvalho, pela concepção teórica do projeto principal com definição de metodologia, redação e revisão. JVC Lima, pela concepção teórica do projeto principal com definição de metodologia, redação e revisão. 


\section{Referências}

1. Brasil. Ministério da Saúde. Saúde da família: uma estratégia para reorientação do modelo assistencial. Brasília: M inistério da Saúde; 1998.

2. Franco TB, M erhy EE. Programa de Saúde da Família (PSF): contradições de um programa destinado à mudança do modelo tecnoassistencial. In: M erhy EE, $M$ agalhães Júnior EM, Rimoli J, Franco TB, Bueno WS, organizadores. 0 trabalho em saúde: olhando e experienciando o SUS no cotidiano. São Paulo: Hucitec; 2003. p. 55-123.

3. M erhy EE. Em busca de ferramentas analisadoras das tecnologias em saúde: a informação e o dia a dia de um serviço, interrogando e gerindo trabalho em saúde. In: M erhy EE, Onocko R. organizadores. Agir em saúde: um desafio para o público. São Paulo: Hucitec; 1997. p. 113-60.

4. Ferreira $A B H$. Novo Dicionário Aurélio: dicionário de língua portuguesa. 3a ed. Rio de Janeiro: Nova Fronteira; 1999.

5. Franco TB, Bueno WS, Merhy EE. O acolhimento e os processos de trabalho em saúde: o caso de Betim (MG). In: M erhy EE, Magalhães Júnior $E M$, Rimoli J, Franco TB, Bueno WS, organizadores. 0 trabalho em saúde: ol hando e experienciando o SU S no cotidiano. São Paulo: Hucitec; 2003. p. 37-54.

6. Malta DC, Reis AT, Merhy EE. Mudando o processo de trabalho na rede pública: alguns resultados da experiência em Belo Horizonte. Saúde Debate 2000; 24(56):21-34.

7. M atumoto S. O acolhimento: um estudo sobre seus componentes e sua produção em uma unidade da rede básica de serviços de saúde [dissertação]. Ribeirão Preto (SP): Escola de Enfermagem de Ribeirão Preto; 1998.

8. Londrina. Prefeitura do M unicípio. Autarquia Municipal de Saúde. Plano M unicipal de Saúde 2004-2005: versão preliminar. Londrina: Prefeitura do Município; 2004.

9. Hartz ZMA. Pesquisa em avaliação da atenção básica: a necessária complementação do monitoramento. Divulg Saúde Debate 2000; (21):29-35.

10. M erhy EE. Programa Saúde da Família: somos contra ou a favor? Saúde Debate 2002; 26 (60):118-122.
11. Peduzzi M, Anselmi ML. O processo de trabalho do auxiliar de enfermagem. In: Brasil. M inistério da Saúde. Formação. Brasília: M inistério da Saúde; 2003. p. 73-87.

12. Westphal MF, Bógus CM, Faria M M. Grupos focais: experiências precursoras em programas educativos em saúde no Brasil. Bol O ficina Sanit Panam 1996; 120(6):472-481.

13. Bardin L 1979. Análise de conteúdo. Lisboa: Edições 70; 1979.

14. Silva Júnior $A G, M$ ascarenhas MT. Avaliação da atenção básica em saúde sob a ótica da integralidade: aspectos conceituais e metodológicos. In: Pinheiro R, $M$ attos RA, organizadores. Cuidado - as fronteiras da integralidade. Rio de Janeiro: Hucitec; 2004. p. 241-257.

15. M erhy EE. Em busca da qualidade dos serviços de saúde: os serviços de porta aberta para a saúde e 0 modelo tecno-assistencial em defesa da vida. In: Cecílio LCO, organizador. Inventando a mudança na saúde. São Paulo: Hucitec; 1994. p. 117-160.

16. Brasil. M inistério da Saúde. A educação permanente entra na roda. Brasília: M inistério da Saúde; 2005.

17. Leitão LRG. Não basta apenas ouvir, é preciso escutar. Saúde Debate 1995; (47):46-49.

18. Brasil. M inistério da Saúde. Curso de formação de facilitadores de Educação Permanente em Saúde. Rio de Janeiro: M inistério da Saúde; 2005.

19. Almeida MCP, Mishima SM. O desafio do trabalho em equipe na atenção à saúde da família: construindo "novas autonomias" no trabalho. Interface (Botucatu) 2001; 9:150-153.

20. Campos GWS. Subjetividade e administração de pessoal: considerações sobre modos de gerenciar o trabalho e equipe de Saúde. In: M erhy EE, Onocko R, organizadores. Agir em saúde: um desafio para o público. São Paulo: Hucitec; 1997. p. 229-266.

Artigo apresentado em 26/03/2007

Aprovado em 30/04/2007

Versão final apresentada em 15/06/2007 